\title{
Vitamin K: food composition and dietary intakes
}

\author{
Sarah L. Booth* \\ Vitamin K Laboratory, USDA Human Nutrition Research Center on Aging at Tufts University, Boston, MA, USA
}

\begin{abstract}
Vitamin $\mathrm{K}$ is present in the diet in the forms of phylloquinone and menaquinones. Phylloquinone, which is the major dietary source, is concentrated in leafy plants and is the vitamin $\mathrm{K}$ form best characterized in terms of food composition and dietary intakes. In contrast, menaquinones are the product of bacterial production or conversion from dietary phylloquinone. Food composition databases are limited for menaquinones and their presence in foods varies by region. Dietary intakes of all forms of vitamin K vary widely among age groups and population subgroups. Similarly, the utilization of vitamin K from different forms and food sources appear to vary, although our understanding of vitamin $\mathrm{K}$ is still rudimentary in light of new developments regarding the menaquinones.
\end{abstract}

Keywords: vitamin K; phylloquinone; menaquinones; food composition; dietary intake

$\mathrm{T}$ he term 'vitamin $\mathrm{K}$ ' represents a family of compounds with a common chemical structure, 2-methyl-1,4-napthoquinone (Fig. 1).

\section{Food sources}

\section{Phylloquinone}

Phylloquinone, also referred to as vitamin $\mathrm{K}_{1}$, is a compound present in all photosynthetic plants (1). Phylloquinone is the primary dietary source of vitamin $\mathrm{K}$. In general, green, leafy vegetables contain the highest known phylloquinone concentrations and contribute approximately $60 \%$ of total phylloquinone intake $(2$, 3). As indicated in Table 1, spinach and collards, which have concomitant high concentrations of chlorophyll associated with the photosynthetic process, hence, dark leaf color have substantially higher concentrations of phylloquinone compared to the more commonly consumed iceberg lettuce, which is substantially paler, hence, lower chlorophyll concentrations. The other plant sources of phylloquinone are certain plant oils including soybean, canola (also known as rapeseed), cottonseed, and olive (Table 1). Margarine, spreads, and salad dressings derived from these plant oils are important dietary sources of phylloquinone $(4,5)$. Plant oils are used for preparation of multiple mixed dishes, hence many commercially prepared foods including baked goods also contain small amounts of phylloquinone. Although multiple databases now exist that contain some phylloquinone contents of foods $(6,7)$, the most extensive analysis of phylloquinone in common foods using established food sampling protocols (8) are found in the United States Department of Agriculture (USDA) Nutrient Database for Standard Reference (http:// www.ars.usda.gov/SP2UserFiles/Place/12354500/Data/SR 22/nutrilistsr22a430.pdf; accessed 05.22.10).

\section{2',3'-Dihydrophylloquinone}

The commercial hydrogenation of phylloquinone-rich oils results in a transformation of phylloquinone into a hydrogenated form, 2',3'-dihydrophylloquinone (9). As expected, trans fatty acid concentrations are highly correlated with dihydrophylloquinone concentrations (10). In the US food supply commercial hydrogenation of plant oils was a common practice that prolonged shelf life of the oil-based products. Many foods sold in fast-food restaurants and frozen prepared products such as fast-food French fries, doughnuts, and breaded fish sticks contained high concentrations of $2^{\prime}, 3^{\prime}$-dihydrophylloquinone (5) (Table 1). However, with current controversy regarding the health consequences of trans fatty acid intake (11), there have been regional trans fat bans in the US food supply. It is anticipated that the decrease in hydrogenation of plant oils will also reduce the presence of dihydrophylloquinone in the US food supply, hence monitoring of this form of vitamin $\mathrm{K}$ in the food supply is warranted. Unlike trans fatty acids, dihydrophylloquinone is only present in hydrogenated 
(A)<smiles>CC1=CC(=O)c2ccccc2C1=O</smiles>

(C)<smiles>CC(C)=CCCC(C)=CCC1=C(C)C(=O)c2ccccc2C1=O</smiles>

(B)<smiles>CC(C)=CCCCC(C)C</smiles>

(D)<smiles>CC(C)=CCCC(C)=CCC1=C(C)C(=O)c2ccccc2C1=O</smiles>

Fig. 1. Forms of vitamin K. (A) Menadione, which is present in animal feed; (B) phylloquinone, which is the primary dietary source; (C) menaquinone-4, which is a conversion product from menadione or phylloquinone; and (D) menaquinones, which can vary in length from MK-4 to MK-13.

plant oils, hence monitoring this form of vitamin $\mathrm{K}$ in the food supply is a robust approach to monitoring the practice of commercial hydrogenation of plant oils.

\section{Menaquinones}

Menaquinones are the other category of vitamin K present in the food supply (Fig. 1). Menaquinones are often referred to as Vitamin $\mathrm{K}_{2}$, which is somewhat misleading given that all menaquinones are not alike in their origin or their function. Menaquinones are primarily of bacterial origin, and differ in structure from phylloquinone in their 3-substituted lipophilic side chain. The major menaquinones contain 4-10 repeating isoprenoid units indicated by MK-4 to MK-10; forms up to 13 isoprenoid groups have been identified.

Menaquinone-4 (MK-4) (Fig. 1) is unique among the menaquinones in that it is not of bacterial origin. Instead, MK-4 is formed by a realkylation step from menadione present in animal feeds or is the product of tissue-specific conversion directly from dietary phylloquinone $(12,13)$.

Table 1. Vitamin K content of common foods

\begin{tabular}{|c|c|c|c|}
\hline Food & Major form of vitamin $\mathrm{K}$ & Concentration $(\mu \mathrm{g} / \mathrm{l} 00 \mathrm{~g})$ & References $^{\mathrm{a}}$ \\
\hline \multicolumn{4}{|c|}{ Vegetables } \\
\hline Collards & Phylloquinone & 440 & (39) \\
\hline Spinach & Phylloquinone & 380 & (39) \\
\hline Broccoli & Phylloquinone & 180 & (39) \\
\hline Cabbage & Phylloquinone & 145 & (39) \\
\hline Iceberg lettuce & Phylloquinone & 35 & (39) \\
\hline \multicolumn{4}{|c|}{ Fats and oils } \\
\hline Soybean oil & Phylloquinone & 193 & (5) \\
\hline Canola oil & Phylloquinone & 127 & (5) \\
\hline Cottonseed oil & Phylloquinone & 60 & $(5)$ \\
\hline Olive oil & Phylloquinone & 55 & $(5)$ \\
\hline \multicolumn{4}{|c|}{ Mixed dishes ${ }^{\mathrm{b}}$} \\
\hline Fast food french fries & Dihydrophylloquinone & 59 & $(40)$ \\
\hline Fast food nachos & Dihydrophylloquinone & 60 & $(40)$ \\
\hline Frozen, breaded fish sticks & Dihydrophylloquinone & 16 & $(40)$ \\
\hline Margarine with hydrogenated oil & Dihydrophylloquinone & 102 & $(5)$ \\
\hline \multicolumn{4}{|c|}{ Other foods } \\
\hline Natto & Menaquinone-7 & 998 & (6) \\
\hline Hard cheeses & Menaquinone-9 & 51.1 & (6) \\
\hline Soft cheeses & Menaquinone-9 & 39.5 & (6) \\
\hline
\end{tabular}

${ }^{a}$ References are the primary data source. However, numbers in this table are indicative of median concentrations of all analysis for a given food in the author's laboratory and may differ from reference because of the inclusion of unpublished data.

${ }^{b}$ These data reflect the content when hydrogenated phylloquinone-rich oils are used. When non-hydrogenated oils are used, the predominant form would be phylloquinone. 
In the United States, menadione is the synthetic form of vitamin $\mathrm{K}$ used in poultry feed. As such, MK-4 formed from menadione is present in poultry products in the US food supply (14). However, MK-4 formed from phylloquinone is limited to organs not commonly consumed in the diet including kidney. The exceptions are dairy products with MK-4 found in milk, butter, and cheese, albeit in modest amounts. Therefore it is unlikely that MK-4 is an important dietary source of vitamin $\mathrm{K}$ in food supplies that do not use menadione for poultry feed nor are rich in dairy products.

There is growing interest in the health benefits of longer-chain menaquinones, which are limited to certain foods in the food supply. Menaquinone-7 (MK-7) is primarily the product of fermentation using bacillus subtilis natto and is present in a traditional Japanese soybean-based product called natto. Natto contains approximately 2.5 times more MK-7 compared to the phylloquinone content of spinach (Table 1). Natto also contains MK-8 and phylloquinone ( 84 and $35 \mu \mathrm{g} / 100 \mathrm{~g}$, respectively), although both are modest in concentration compared to MK-7 (6). Some cheeses also contain MK-8 and MK-9 (6), but these are dependent on cheese production practices, hence the food composition databases are limited in their ability to characterize menaquinone intake across different food supplies.

\section{Dietary intakes}

The current US dietary guidelines for intakes of vitamin $\mathrm{K}$ are 90 and $120 \mu \mathrm{g} / \mathrm{day}$ for women and men, respectively (15). These guidelines are termed adequate intakes (AI) because the Institute of Medicine concluded in 2001 that there were insufficient data available to generate a precise recommendation for vitamin $\mathrm{K}$. The AI values for vitamin $\mathrm{K}$ were generated from the Third National Health and Nutrition Examination Survey (NHANES III, 1988-1994) and based on the median phylloquinone intake in the United States for each age and gender category (15). In the absence of abnormal bleeding associated with low vitamin $\mathrm{K}$ intakes among adults, it was assumed that the current intakes are adequate. However, the adequacy of intake defined by an absence of bleeding is controversial. Furthermore, the elderly report median intakes below the current AI for adults. As reviewed elsewhere (16), there is controversy regarding biochemical measures of subclinical vitamin K deficiency and as a consequence, the true dietary requirement of vitamin $\mathrm{K}$ is unknown. For the purpose of this review, dietary intakes of vitamin $\mathrm{K}$ will be presented relative to the current AI. By comparison, the guidelines in the United Kingdom are $1 \mu \mathrm{g} / \mathrm{kg}$ body/day (17) and are set at $75 \mu \mathrm{g} /$ day for adult men, $60 \mu \mathrm{g} /$ day for women, aged 18 29 year, and $65 \mu \mathrm{g} /$ day for women 30 years and over in Japan (18).
Estimates of phylloquinone intake in various populations are probably more accurate than intakes of other forms of vitamin $\mathrm{K}$ and there is a substantial difference in the reported intakes from a number of countries, which seems to be related to food consumption practices in different areas (18-23). For example, the mean reported vitamin $\mathrm{K}$ intake of young Japanese women (mean 21.2 years, $n=124)$ was about $230 \mu \mathrm{g} /$ day (18). The estimated phylloquinone intakes in northern China, England, and Scotland were 247, 103, and $70 \mu \mathrm{g} / \mathrm{day}$, respectively $(23,24)$. Of note, phylloquinone intakes have been decreasing over the last two decades in the United Kingdom, consistent with a concomitant decline in leafy green vegetable consumption (25). Based on the NHANES III data, the elderly (defined as older as 71 years of age) have median phylloquinone intakes lower than the current AI ( 89 and $79 \mu \mathrm{g} /$ day for women and men, respectively). This observation supports the findings of others who have reported very low phylloquinone intakes among those in nursing homes (26) and those with Alzheimer's disease (27). Given emerging association of low vitamin $\mathrm{K}$ intakes with risk of certain diseases such as cardiovascular disease and osteoarthritis (16), the elderly present a potentially vulnerable subgroup of the population with respect to vitamin $\mathrm{K}$.

Very little is known about the contribution of dietary menaquinones to overall vitamin $\mathrm{K}$ nutrition and although it has been stated that approximately $50 \%$ of the daily requirement for vitamin $\mathrm{K}$ is supplied by the gut flora through the production of menaquinones, there is little evidence to support this estimate (28). In one study among adults with acute bacterial overgrowth as induced by omeprazole, menaquinones produced by these bacteria had some contribution to vitamin $\mathrm{K}$ status during dietary phylloquinone restriction, but not enough to restore biochemical measures of vitamin back to normal range (29).

As previously indicated, there are regional differences in the forms and content of menaquinones in the food supply. For example, natto is unique to a traditional Japanese diet whereas the cheeses that contain high concentrations of MK-8 and MK-9 appear to be most prevalent in European dairy producing food supplies. Although there are reported menaquinone intakes, these are limited to studies from Japan (18) and the Netherlands (21), and are low compared to phylloquinone intakes. In the United States, menaquinones are limited in the food supply and have not been systematically assessed.

\section{Are all forms of vitamin $\mathrm{K}$ the same?}

There are surprisingly little data on the relative biological availability of different forms of vitamin $\mathrm{K}$ among different food sources. Furthermore, there is a growing body of literature to suggest that our understanding of 
vitamin $\mathrm{K}$ is still rudimentary in light of new developments regarding different forms.

As previously stated, phylloquinone is of plant origin, with absolute intakes being predominantly from green leafy vegetables. Phylloquinone is tightly bound to the membranes of plant chloroplasts, and is less bioavailable compared to phylloquinone obtained from plant oils and/ or dietary supplements (30). Some estimates place the absorption of phylloquinone to be $10 \%$ from plants compared to supplements (31). However there appear to be differences in absorption compared to the plant species, with phylloquinone obtained from broccoli and collards having greater absorption compared to spinach $(31,32)$. Similarly, and not unexpected because vitamin K is lipophilic, addition of a fat source to the meal results in higher absorption. For a more comprehensive review of vitamin $\mathrm{K}$ absorption, the readers are referred elsewhere (33).

Phylloquinone differs from $2^{\prime}, 3^{\prime}$-dihydrophylloquinone by a saturation of a single bond at the $2^{\prime}, 3^{\prime}$ position of the side chain (9). Surprisingly this single substitution results in a lower absorption of dihydophylloquinone compared to an equimolar amount of phylloquinone (34). There is also indirect evidence of lower activity of dihydrophylloquinone as an enzyme cofactor, which currently is the only known function of vitamin $\mathrm{K}$. The implications of this poor bioavailability and activity are currently unknown, although at least one study suggests a detrimental effect on bone mineral density among older adults in a community-based cohort (35). The potential impact of poor utilization of dihydrophylloquinone on bone health will be of little importance in the future should hydrogenated oils be removed from the food supply.

The menaquinones are poorly understood in terms of vitamin $\mathrm{K}$ absorption and utilization. MK-7, when administered in the form of natto in equimolar amounts to phylloquinone administered in the form of spinach, has a peak height difference of more than 10 -fold compared to phylloquinone, with a half-life of 56 hours, compared to 7.5 hours for phylloquinone (36). Whereas all forms of vitamin $\mathrm{K}$ appear to be initially associated with triglyceride-rich lipoproteins (TRL), the longer chain menaquinones including MK-7 and MK-9 are also associated with low-density lipoprotein (LDL). MK-4 has been reported in TRL, LDL, and high density lipoproteins. These preliminary data suggest that the menaquinones have different transport pathways and distribution, which has implications for transport to extra-hepatic tissue such as bone (33).

Emerging studies on MK-4 challenge our current understanding of vitamin $\mathrm{K}$. As demonstrated using stable isotopes, MK-4 is a conversion product of phylloquinone via the intermediate, menadione (37). There appears to be both local and systemic conversion to MK-4, with the local conversion being the predominant pathway. The implications of this conversion are still the topic of speculation. To add complexity to the interpretation is the observation that this conversion does not occur in all tissues. Whereas the liver contains primarily phylloquinone and very long-chain menaquinones, MK-4 is the predominant form in the brain, pancreas, and glands (38). In terms of dietary intakes, MK-4 intakes are low compared to other forms of vitamin K. However, dietary phylloquinone converts to MK-4 in those tissues where MK-4 appears to be required so it is likely that low MK-4 intakes are of little consequence to health when there is adequate dietary phylloquinone available for conversion to MK-4.

In conclusion, much of our understanding of vitamin $\mathrm{K}$ nutrition has focused on the primary dietary source, phylloquinone. There are comprehensive databases available that contain phylloquinone contents of a variety of foods. Dietary assessment of phylloquinone reveals variation in intakes by age and population subgroups. In contrast, the menaquinones are present in the food supply, but there are limited food composition data available. As a corollary, estimates of intakes of menaquinones are very limited and our understanding of their role in vitamin $\mathrm{K}$ nutrition is not well understood.

\section{Conflict of interest and funding}

Based upon work supported by the US Department of Agriculture, Agricultural Research Service under Cooperative Agreement No. 58-1950-7-707, and National Institutes of Health DK069341. Any opinions, findings, conclusions, or recommendations expressed in this publication are those of the authors and do not necessarily reflect the view of the US Department of Agriculture.

\section{References}

1. Gross J, Cho WK, Lezhneva L, Falk J, Krupinska K, Shinozaki $\mathrm{K}$, et al. A plant locus essential for phylloquinone (vitamin K1) biosynthesis originated from a fusion of four eubacterial genes. $\mathbf{J}$ Biol Chem 2006; 281: 17189-96.

2. Thane C, Paul A, Bates C, Bolton-Smith C, Prentice A, Shearer M. Intake and sources of phylloquinone (vitamin K-1): variation with socio-demographic and lifestyle factors in a national sample of British elderly people. Brit J Nutr 2002; 87: 605-13.

3. McKeown NM, Jacques PF, Gundberg CM, Peterson JW, Tucker KL, Kiel DP, et al. Dietary and nondietary determinants of vitamin $\mathrm{K}$ biochemical measures in men and women. J Nutr 2002; 132: 1329-34.

4. Piironen V, Koivu T, Tammisalo O, Mattila P. Determination of phylloquinone in oils, margarines and butter by high-performance liquid chromatography with electrochemical detection. Food Chem 1997; 59: 473-80.

5. Peterson JW, Muzzey KL, Haytowitz D, Exler J, Lemar L, Booth SL. Phylloquinone (vitamin K-1) and dihydrophylloquinone content of fats and oils. JAOCS 2002; 79: 641-6.

6. Schurgers LJ, Vermeer C. Determination of phylloquinone and menaquinones in food. Effect of food matrix on circulating vitamin K concentrations. Haemostasis 2000; 30: 298-307. 
7. Bolton-Smith C, Price RJ, Fenton ST, Harrington DJ, Shearer MJ. Compilation of a provisional UK database for the phylloquinone (vitamin K1) content of foods. Br J Nutr 2000; 83: 389-99.

8. Pehrsson P, Haytowitz D, Holden J, Perry C, Beckler D. USDA's National Food and Nutrient Analysis Program: food sampling. J Food Compos Anal 2000; 13: 379-90.

9. Davidson K, Booth S, Dolnikowski G, Sadowski J. Conversion of vitamin K-1 to 2',3'-dihydrovitamin K1 during the hydrogenation of vegetable oils. J Agric Food Chem 1996; 44: 980-3.

10. Booth SL, Davidson KW, Lichtenstein AH, Sadowski JA. Plasma concentrations of dihydro-vitamin K1 following dietary intake of a hydrogenated vitamin K1-rich vegetable oil. Lipids 1996; 31: 709-13.

11. Lichtenstein AH, Ausman LM, Jalbert SM, Schaefer EJ. Effects of different forms of dietary hydrogenated fats on serum lipoprotein cholesterol levels. N Engl J Med 1999; 340: 1933-40.

12. Davidson RT, Foley AL, Engelke JA, Suttie JW. Conversion of dietary phylloquinone to tissue menaquinone-4 in rats is not dependent on gut bacteria. J Nutr 1998; 128: 220-3.

13. Thijssen HH, Vervoort LM, Schurgers LJ, Shearer MJ. Menadione is a metabolite of oral vitamin K. Br J Nutr 2006; 95: 260-6.

14. Elder SJ, Haytowitz DB, Howe J, Peterson JW, Booth SL. Vitamin $\mathrm{K}$ contents of meat, dairy, and fast food in the U.S. diet. J Agric Food Chem 2006; 54: 463-7.

15. Food and Nutrition Board, Institute of Medicine. Dietary reference intakes for vitamin $\mathrm{A}$, vitamin $\mathrm{K}$, arsenic boron, chromium, copper, iodine, iron, manganese, molybdenum, nickel, silicon, vanadium, and zinc. Washington, DC: National Academy Press; 2001.

16. Booth SL. Roles for vitamin K beyond coagulation. Annu Rev Nutr 2009; 29: 89-110.

17. Dietary reference values for food energy and nutrients for the United Kingdom. Report on health and social subjects no. 41. London: HMSO; 1991.

18. Kamao M, Suhara Y, Tsugawa N, Uwano M, Yamaguchi N, Uenishi $\mathrm{K}$, et al. Vitamin $\mathrm{K}$ content of foods and dietary vitamin $\mathrm{K}$ intake in Japanese young women. J Nutr Sci Vitaminol (Tokyo) 2007; 53: 464-70.

19. Duggan P, Cashman K, Flynn A, Bolton-Smith C, Kiely M. Phylloquinone (vitamin K1) intakes and food sources in 18-64year-old Irish adults. Br J Nutr 2007; 92: 151-8.

20. Food and Nutrition Board, Institute of Medicine. Dietary reference intakes: applications in dietary assessment. A report of the subcommittee on Interpretation and Uses of Dietary Reference Intakes and the Standing Committee on the Scientific Evaluation of Dietary and Reference Intakes. Washington, DC: National Academy Press; 2001.

21. Schurgers L, Geleijnse J, Grobbee D, Pols H, Hofman A, Witteman J, et al. Nutritional intake of vitamins K1 (phylloquinone) and K2 (menaquinone) in the Netherlands. J Nutr Environ Med 1999; 9: 115-22.

22. Thane CW, Paul AA, Bates CJ, Bolton-Smith C, Prentice A, Shearer MJ. Intake and sources of phylloquinone (vitamin K1): variation with socio-demographic and lifestyle factors in a national sample of British elderly people. Br J Nutr 2002; 87 : 605-13.

23. Yan L, Zhou B, Greenberg D, Wang L, Nigdikar S, Prynne C, et al. Vitamin $\mathrm{K}$ status of older individuals in northern China is superior to that of older individuals in the UK. Br J Nutr 2004; 92: 939-45.

24. Bolton-Smith C, Shearer MJ. Dietary reference values for vitamin K: where are we now? Nutr Food Sci 1997; 6: 242-5.
25. Thane CW, Bolton-Smith C, Coward WA. Comparative dietary intake and sources of phylloquinone (vitamin K1) among British adults in -7 and 2000-1. Br J Nutr ; 96 1986; 2006: 1105-15.

26. Tse SL, Chan TY, Wu DM, Cheung AY, Kwok TC. Deficient dietary vitamin $\mathrm{K}$ intake among elderly nursing home residents in Hong Kong. Asia Pac J Clin Nutr 2002; 11: 62-5.

27. Shatenstein B, Kergoat MJ, Reid I. Poor nutrient intakes during 1-year follow-up with community-dwelling older adults with early-stage Alzheimer dementia compared to cognitively intact matched controls. J Am Diet Assoc 2007; 107: 2091-9.

28. Suttie JW. The importance of menaquinones in human nutrition. Annu Rev Nutr 1995; 15: 399-417.

29. Paiva SA, Sepe TE, Booth SL, Camilo ME, O'Brien ME, Davidson $\mathrm{KW}$, et al. Interaction between vitamin $\mathrm{K}$ nutriture and bacterial overgrowth in hypochlorhydria induced by omeprazole. Am J Clin Nutr 1998; 68: 699-704.

30. Booth SL, Suttie JW. Dietary intake and adequacy of vitamin K. J Nutr 1998; 128: 785-8.

31. Garber AK, Binkley NC, Krueger DC, Suttie JW. Comparison of phylloquinone bioavailability from food sources or a supplement in human subjects. J Nutr 1999; 129: 1201-3.

32. Booth SL, Lichtenstein AH, Dallal GE. Phylloquinone absorption from phylloquinone-fortified oil is greater than from a vegetable in younger and older men and women. J Nutr 2002; 132: 2609-12.

33. Shearer MJ, Newman P. Metabolism and cell biology of vitamin K. Thromb Haemost 2008; 100: 530-47.

34. Booth SL, Lichtenstein AH, O'Brien-Morse M, McKeown NM, Wood RJ, Saltzman E, et al. Effects of a hydrogenated form of vitamin $\mathrm{K}$ on bone formation and resorption. Am J Clin Nutr 2001; 74: 783-90.

35. Troy LM, Jacques PF, Hannan MT, Kiel DP, Lichtenstein AH, Kennedy ET, et al. Dihydrophylloquinone intake is associated with low bone mineral density in men and women. Am J Clin Nutr 2007; 86: 504-8.

36. Schurgers LJ, Vermeer C. Differential lipoprotein transport pathways of K-vitamins in healthy subjects. Biochim Biophys Acta 2002; 1570: 27-32.

37. Okano T, Shimomura Y, Yamane M, Suhara Y, Kamao M, Sugiura M, et al. Conversion of phylloquinone (vitamin K1) into menaquinone-4 (vitamin K2) in mice: two possible routes for menaquinone-4 accumulation in cerebra of mice. J Biol Chem 2008; 283: 11270-9.

38. Thijssen HH, Drittij-Reijnders MJ. Vitamin K status in human tissues: tissue-specific accumulation of phylloquinone and menaquinone-4. Br J Nutr 1996; 75: 121-7.

39. Damon M, Zhang NZ, Haytowitz DB, Booth SL. Phylloquinone (vitamin K-1) content of vegetables. J Food Compos Anal 2005; 18: 751-8.

40. Dumont JF, Peterson J, Haytowitz D, Booth SL. Phylloquinone and dihydrophylloquinone contents of mixed dishes, processed meats, soups and cheeses. J Food Compos Anal 2003; 16: 595-603.

\footnotetext{
*Sarah L. Booth

USDA Human Nutrition Research Center on Aging at Tufts University 7II Washington St.

Boston, MA 021 II

Tel: 6165563231

Fax: 6175563149

Email: sarah.booth@tufts.edu
} 